\title{
IDENTITIES AND INEQUALITIES FOR THE COSINE AND SINE FUNCTIONS
}

\author{
IOSIF PINELIS
}

Abstract. Identities and inequalities for the cosine and sine functions are obtained.

Mathematics subject classification (2010): 26D05, 26D15, 40A25, 41A58.

Keywords and phrases: Inequalities, trigonometric functions, cosine function, sine function, Bessel function, series expansions, approximations.

\section{REFERENCES}

[1] P. J. DAvis, Interpolation and approximation, Blaisdell Publishing Co. Ginn and Co. New YorkToronto-London, 1963.

[2] T. N. E. GREVILLE, A generalization of Waring's formula, Ann. Math. Statistics, 15:218-219, 1944.

[3] S. Karlin And J. M. Karon, On Hermite-Birkhoff interpolation, J. Approximation Theory, 6:90115, 1972., Collection of articles dedicated to J. L. Walsh on his 75th birthday, V (Proc. Internat. Conf. Approximation Theory, Related Topics and their Applications, Univ. Maryland, College Park, Md., 1970).

[4] G. Mastroianni and G. V. Milovanović, Interpolation processes, Springer Monographs in Mathematics. Springer-Verlag, Berlin, 2008., Basic theory and applications.

[5] G. V. Milovanović, Corrigendum: "Least squares approximation with constraints", Math. Comp., 48(178):854, 1987

[6] G. V. Milovanović AND S. WRIGGe, Least squares approximation with constraints, Math. Comp., 46(174):551-565, 1986.

[7] A. SPitZBART, A generalization of Hermite's interpolation formula, Amer. Math. Monthly, 67:42-46, 1960.

[8] E. T. Whittaker And G. N. Watson, A course of modern analysis, Cambridge Mathematical Library. Cambridge University Press, Cambridge, 1996., An introduction to the general theory of infinite processes and of analytic functions; with an account of the principal transcendental functions, Reprint of the fourth (1927) edition. 